\title{
Evaluation of use of Signal system of blood culture in paediatrics
}

\author{
H FOX, D E HEALING, R H GEORGE Department of Microbiology, Birmingham Children's \\ Hospital
}

SUMMARY A new method of blood culture, the Signal system (Oxoid), was assessed in paediatric practice. Isolation rates of pathogens, frequency of contamination (false positive results), and time taken to detect positive cultures were analysed. Four hundred and seventy nine organisms were isolated from 457 of 3000 cultures collected, of which 283 organisms were considered to be clinically important. The overall rate of positive cultures was $15 \cdot 2 \%$, and clinically important organisms were isolated from $9 \cdot 1 \%$, giving an overall contamination rate of $6 \cdot 1 \%$. The rate of contamination with Gram positive bacilli was $1 \cdot 1 \%$ and coagulase negative staphylococci $4 \cdot 2 \%$. Over $51 \cdot 6 \%$ of all isolates were detected within 24 hours, $81 \%$ within 48 hours, and $86 \%$ within three days: $91 \cdot 1 \%$ of clinically important organisms were isolated within three days. Unimportant organisms tended to give a delayed signal, although this sometimes occurred with Candida spp, Klebsiella spp, Pseudmomonas spp and a small number of other such organisms. Four hundred and forty nine of the 457 positive cultures gave a visible signal. Six of seven isolates of Haemophilus influenzae failed to give a signal, as did two coagulase negative staphylococci.

The Signal system is a convenient and cost effective method of blood culture.

Blood cultures are some of the most important specimens received in microbiology laboratories. Rapid detection of bacteraemia is essential as it allows direct spectrum antibiotics to be used. Conventional blood cultures are subcultured, often repeatedly, to assist in rapid diagnosis, but this can lead to contamination and hence false positive results. ${ }^{1}$

Newer automated methods have recently been introduced. These include the radiometric method, which detects radioactive carbon dioxide produced from $\mathrm{C}^{14}$ labelled substrates (Bactec, Johnson Laboratories), ${ }^{2}$ and a spectrophotometric method using infrared to detect growth (Bactec, Johnson Laboratories). Another method relies on changes in the electrical impedance of the culture medium during growth (Malthus Instruments Ltd). ${ }^{3}$ These systems all require large initial capital expenditure and recurring maintenance costs.

An alternative non-automated culture technique, using a biphasic culture system (Septi Chek System, Roche Diagnostics) ${ }^{4}$ has recently been introduced. This increases the chance of detecting organisms, gives quick results, and requires minimal capital outlay. Another has a lysis centrifugation step to concentrate organisms (Du Pont Isolator, Du Pont Co). ${ }^{5}$ A novel system, which gives a visual signal (Signal system,

Accepted for publication 18 February 1988
Oxoid Ltd) has been produced and has been evaluated in adults. ${ }^{67}$

Ideally new systems of blood culture should be evaluated in parallel with existing methods, but this is seldom practical in infants and small children as the volume of blood is small. Evaluation of new systems in adults cannot be easily applied to children as the type and incidence of pathogens differs. ${ }^{8}$ Samples are also more difficult to obtain, which influences the rate of contamination. The inoculum size will also be influenced by sample volume and number of organisms in each unit volume, both of which are different in adults and children. Inoculum size influences the rate of detection of positive cultures. ${ }^{8-11}$

\section{Material and methods}

Blood cultures collected at Birmingham Children's Hospital between October 1986 and December 1987 from infants and children, aged from under 24 hours to 16 years, were included in the study. Cultures collected from June 1987 from neonates at Birmingham Maternity Hospital were included. Sample volumes up to a maximum of $10 \mathrm{ml}$ were collectedmost by venepuncture, but a small number via intravascular cannulae. Bottles were transported to the laboratory as soon as was practicable, and the Signal device was inserted after the cap had been 
disinfected with alcohol. Bottles were incubated at $37^{\circ} \mathrm{C}$ for seven days, unless endocarditis or fungal infection was suspected, when they were incubated for 14 days.

In the early part of the study bottles were shaken twice manually during the first 24 hours. Subsequently the manufacturer recommended frequent agitation during the first 24 hours to increase the rate of development of a positive signal. We swirled the bottles on an orbital shaker (Luckham), fitted with a programmable timer, for eight periods of 30 minutes, with a stationary interval of two and a half hours. All cultures at Birmingham Maternity Hospital were processed using mechanical agitation. Bottles were observed two to eight times daily during the incubation period. Positive cultures were indicated by culture medium being forced into the trap on the top of the signal device - that is, producing a visible signal; turbidity, colonies, or haemolysis could also be observed as with conventional blood culture bottles. When a signal was noted, a sample was withdrawn aseptically from the trap for microscopy and subculture and the time taken for a positive result was recorded. Bottles were then reincubated to detect polymicrobial baceteraemias. At the end of the incubation period negative bottles were swirled and 10 $\mathrm{ml}$ of air was injected through the injection port on the Signal device. This displaced culture medium from the bottle into the trap which produced subculture.

Subcultures were incubated under aerobic conditions on Columbia blood agar and Isosensitest agar (Oxoid Ltd-CM 473) with added haematin (12.5 mg/ $1)$, nicotinamide adenine dinucleotide $(12.5 \mathrm{mg} / \mathrm{l})$, and $5 \%$ lysed horse blood. Anaerobic subculture was performed on Columbia blood agar (BBL Ltd) with $5 \%$ added horse blood and neomycin $(50 \mathrm{mg} / \mathrm{l})$ using a Gas-Pak system (BBL Ltd). Where Gram stain of positive cultures suggested a fungal or Gram negative aetiology, subcultures were also made on MacConkey agar or Sabouraud agar. Organisms were identified by standard laboratory methods. When positive isolates were obtained, a medically qualified microbiologist visited the ward and jointly evaluated the relevance with the clinician.

\section{Results}

Three thousand blood cultures were examined during the study, of which the first $255(6.7 \%)$ were processed with manual shaking. Four hundred and fifty seven bottles grew 479 different organisms, and a visible signal was observed with 449 bottles. Haemophilus influenzae was isolated from six of the remaining culture positive bottles and coagulase negative staphylococci from two. Two isolates of $H$ influenzae were isolated on terminal subcultures on day 7 , two
Table 1 Time of detection of Gram negative organisms

\begin{tabular}{|c|c|c|c|c|c|}
\hline & \multirow[b]{2}{*}{$(n=)$} & \multicolumn{4}{|c|}{ Time (hours) } \\
\hline & & $<24$ & $24-48$ & $48-72$ & $>72$ \\
\hline Escherichia coli & 30 & 29 & & & 1 \\
\hline Klebsiella aerogenes & 15 & 11 & & 1 & 3 \\
\hline Enterobacter cloacae & 10 & 9 & 1 & & \\
\hline Klebsiella oxytoca & 5 & 5 & & & \\
\hline Serratia marcescens & 4 & 4 & & & \\
\hline Citrobacter koseri & 2 & 1 & 1 & & \\
\hline Salmonella typhi & 2 & 2 & & & \\
\hline Salmonella thompson & 1 & 1 & & & \\
\hline Proteus mirabilis & 1 & & & 1 & \\
\hline Pseudomonas maltophilia & 5 & & 3 & & 2 \\
\hline Pseudomonas aeruginosa & 5 & 1 & 3 & & 1 \\
\hline Acinetobacter calcoaceticus & 1 & & 1 & & \\
\hline Haemophilus influenzae & 7 & 2 & 1 & 1 & 3 \\
\hline $\begin{array}{l}\text { Haemophilus para- } \\
\text { haemolyticus }\end{array}$ & 1 & 1 & & & \\
\hline Neisseria meningitidis & 1 & & & 1 & \\
\hline Moraxella sp & 1 & & & & 1 \\
\hline $\begin{array}{l}\text { Bacteroides sp } \\
\text { Unidentified Gram }\end{array}$ & 1 & & & 1 & \\
\hline negative bacilli & 4 & 2 & & & 2 \\
\hline $\begin{array}{l}\text { Unidentified Gram } \\
\text { negative coccus }\end{array}$ & 1 & & 1 & & \\
\hline Total & 97 & 68 & 11 & 5 & 13 \\
\hline
\end{tabular}

when the bottles were noted to be turbia on tne rourth day, and the other two from blind subcultures after 18 and 12 hours of incubation. The first isolate of coagulase negative staphylococci, which failed to give a visible signal, was visually detected after 24 hours and the other, from a different patient, on terminal subculture of a visually normal bottle. One bottle was subcultured on the third day, because colonies were noted and yielded Neisseria menigitidis by the following day, at which time the signal was positive.

The species of organism isolated and time taken for a positive culture to be obtained is given in tables 1 and 2. Overall, $51 \cdot 6 \%, 80.6 \%$, and $85.8 \%$ of organisms were detected within 24,48 , and 72 hours of collection, and $86.5 \%$ of Gram negative organisms and $84.9 \%$ of Gram positive organisms within 72 hours. Sixty one

Table 2 Time of detection of Gram positive organisms

\begin{tabular}{|c|c|c|c|c|c|}
\hline & & Time & (hours) & & \\
\hline & $(n=)$ & $<24$ & $24-48$ & $48-72$ & $>72$ \\
\hline $\begin{array}{l}\text { Coagulase negative } \\
\text { staphylococci } \\
\text { Staphylococcus aureus } \\
\text { Viridans streptococci } \\
\text { Streptococcus pneumoniae } \\
\text { Faecal streptococci } \\
\beta \text {-haemolytic streptococci* } \\
\text { Listeria monocytogenes } \\
\text { Propionibacterium spp } \\
\text { Corynebacterium spp } \\
\text { Bacillus spp } \\
\text { Candida spp } \dagger \\
\text { Total }\end{array}$ & $\begin{array}{r}227 \\
44 \\
30 \\
16 \\
14 \\
8 \\
1 \\
17 \\
12 \\
5 \\
8 \\
382\end{array}$ & $\begin{array}{r}93 \\
30 \\
20 \\
15 \\
13 \\
6 \\
1\end{array}$ & $\begin{array}{r}107 \\
8 \\
6 \\
1 \\
1\end{array}$ & $\begin{array}{r}13 \\
2 \\
1 \\
1 \\
1\end{array}$ & $\begin{array}{r}17 \\
9 \\
1 \\
7 \\
55\end{array}$ \\
\hline
\end{tabular}

*Includes four group B streptococci; three group G streptococci, one group $\mathbf{A}$ streptococcus.

†Includes two Candida albicans and six $C$ parapsilosis. 
Table 3 Importance of 479 isolates

\begin{tabular}{|c|c|c|c|}
\hline Species & $\begin{array}{l}\text { No of } \\
\text { Isolates }\end{array}$ & $\begin{array}{l}\text { No } \\
\text { clinically. } \\
\text { important }\end{array}$ & $\begin{array}{l}\text { No of con- } \\
\text { taminants }\end{array}$ \\
\hline \multicolumn{4}{|l|}{ Coagulase negative } \\
\hline Staphylococcus aureus & 44 & 40 & 4 \\
\hline Viridans streptococci & 30 & 19 & 11 \\
\hline Streptococcus pneumoniae & 16 & 16 & 0 \\
\hline Faecal streptococci & 14 & 11 & 3 \\
\hline$\beta$-haemolytic streptococci & 8 & 8 & 0 \\
\hline Listeria monocylogenes & 1 & 1 & 0 \\
\hline Gram positive bacilli* & 34 & 0 & 34 \\
\hline Candida spp & 8 & 8 & 0 \\
\hline Escherichia coli & 30 & 23 & 7 \\
\hline Klehsiella Enterobacter spp & 30 & 26 & 4 \\
\hline Other Enterobacteriaceae & 10 & 8 & 2 \\
\hline Pse'udomonas spp & 10 & 10 & 0 \\
\hline Ha'mophilus spp & 8 & 8 & 0 \\
\hline Ve'isseria meningitidis & 1 & 1 & 0 \\
\hline Bacle'roide's sp & $i$ & 1 & 0 \\
\hline Other Gram negative cultures & 7 & 4 & 3 \\
\hline Total & 479 & 283 & 196 \\
\hline
\end{tabular}

*Includes Bacillus spp. Cor!nehacterium spp. Propionibacterium spp.

and a half per cent of clinically important organisms were isolated within 24 hours, $86.9 \%$ within 48 hours, and $91.1 \%$ within three days.

Delayed signals were obtained on 10 occasions with Gram negative cultures; these were more commonly observed with Klebsiella aerogenes, Pseudomonas spp, and non-fermenting Gram negative bacilli. Delayed signals were noted particularly with contaminating Gram positive cultures, 12 of 14 delayed signals due to coagulase negative staphylococci, and all isolates of both Propionibacterium spp and Corynebacterium spp. Overall. $16 \%$ of all the bottles were positive and the rate of clinically important cultures was $9 \cdot 1 \%$. The clinical importance of various organisms is shown in table 3. All isolates of Streptococcus pneumoniae gave positive signals within 48 hours; two of these were sterile on subculture, although microscopy showed Gram positive diplococci, and counterimmunoelectrophoresis, using pneumococcal antisera, confirmed their identity.

Twenty cultures grew mixed organisms. Five of these, isolated from patients with intravascular cannulae, yielded faecal or viridans streptococci plus coagulase negative staphylococci, and were thought to be clinically important; one of these patients had a concurrent urinary tract infection with a faecal streptococcus. Three cultures from one patient and one from another yielded Klebsiella aerogenes and Escherichia coli, and another from a leukaemic patient with an intravascular cannula and a chest infection yielded coagulase negative staphylococci and Haemophilus parainfluenzae.

\section{Discussion}

The evaluation of new blood culture systems in children is difficult because of the small volumes of blood available. A recent study showed that the mean volume of blood taken from neonates was $1.05 \mathrm{ml}$ (range 0.11-3.05 ml). ${ }^{13}$ Comparative studies in children inevitably result in reduced volumes of blood being added to individual culture media. Two previous studies showed that a significant number of paired culture media were inoculated with widely differing volumes of blood. ${ }^{14}$ is In the study by Welsh et al $26 \%$ of clinically important positive cultures were excluded from their analysis because of inoculum differences, and despite this the Isolator method missed $14 \%$ of such organisms and the conventional method $12 \% .^{15}$ We therefore evaluated the Signal system (Oxoid) in a non-comparative study.

The criteria for a successful blood culture system in infants and children are that it must detect the full range of pathogens which may be encountered; enable rapid detection of the pathogen; and have an acceptably low rate of contamination of the system. In a study of 2348 positive cultures, including contaminants, using the Bactec radiometric method, Meadow and Schwartz detected $17 \%, 72 \%$, and $88 \%$ of organisms within 24,48 , and 72 hours, respectively. ${ }^{16}$ This compares with our findings of $51 \cdot 6 \%, 80 \cdot 6 \%$, and $85.8 \%$ at the same times. Meadow and Schwartz also reported that detection of positive cultures after 72 hours occurred particularly with group D streptococci, Candida species, S epidermidis, Klebsiella spp, $S$ aureus, $H$ influenzae, Bacillus spp, diphtheroids, and Propionibacterium spp. ${ }^{16}$ We noted delayed detection of these organisms, although in our study there were no delayed isolates of faecal streptococci. Full details of the speed of detection of organisms by the Dupont Isolator have been lacking in paediatric reports, but Carey reported that the mean time of detection with the Isolator was $4 \cdot 1$ hours faster than with the Bactec. ${ }^{14}$

During the early part of our study Pseudomonas maltophilia gave positive signals in two manually shaken cultures on the fifth day. Subsequently, a further three cultures from this patient gave positive signals within 72 hours when shaken mechanically. While we cannot exclude the possibility that these differences were due to inoculum size, we have noticed that positive signals sometimes develop immediately after one of the shaking periods, and feel that this procedure hastens the development of positive signals. It should be noted that during the period of manual shaking of cultures $37.5 \%$ of coagulase negative staphylococci gave a delayed signal (positive after 72 hours); since we have used an orbital shaker only eight of the 211 isolates $(3.8 \%)$ have given delayed signals. It should also be noted that clinically important organisms gave delayed signals on several occasions when patients were taking antibiotics.

The failure of $\boldsymbol{H}$ influenzae to give a signal is of 
The failure of $H$ influenzae to give a signal is of concern. In view of the importance of this organism we feel blind subculture after 24 hours is advisable in cases of suspected meningitis or epiglottitis. During the study period Propionibacterium spp and one isolate of Bacteroides sp were the only anaerobic organisms isolated, but the system has previously been shown to be capable of growing clinically important anaerobes. ${ }^{67}$ Coagulase negative staphylococci accounted for $35 \%$ of the clinically important organisms isolated at Birmingham Children's Hospital during the study period, an increase on the $11.6 \%$ previously reported from this laboratory ${ }^{18}$; this was almost entirely due to an increase in bacteraemias associated with intravascular cannulae.

The frequency with which we isolated clinically unimportant organisms was $6.9 \%$, which we attribute to contamination at the bedside, as the Signal systcm was not routinely subcultured until day 7 ; the difficulty in collecting samples from infants and small children probably accounted for this. The stringent criteria we applied in our analyses may have overestimated the number of contaminants. Overall, the isolation rate of contaminants is lower than what we previously observed using conventional blood cultures. Corynebacterium spp, Propionibacterium spp, and Bacillus spp were isolated from $1 \cdot 1 \%$ of cultures whereas we previously isolated these from $5.5 \%$ of our cultures, often together with coagulase negative staphylococci. In the past we suspected that most of our unimportant isolates from conventional blood cultures entered the bottle at the time of subculture, and the lower isolation rates in the present study would support that hypothesis. Reported rates of contamination with conventional blood culture systems vary because of variations in the number, timing, and method of subculture. Rates of contamination with the Isolator range from $8.7 \%-23 \%{ }^{14} 151719$ and have been reported to be $1.3 \%$ $3.1 \%$ with the Bactec radiometric method..$^{1317}$

A laboratory processing 2000 cultures a year could currently expect to pay about $£ 1.85$ for each complete Signal system. This compares favourably with many commercially produced two bottle conventional blood culture systems. It is, however, more expensive than blood culture media produced "in-house". If the savings on reduced numbers of subcultures, investigation of probable contaminants, and savings in the time needed to assess the importance of contaminants are considered, the Signal system is highly cost effective.

In conclusion, the Signal system combines satisfactory speed of detection of bacteraemia with low rates of laboratory contamination. We recommend blind subculture for Haemophilus in cases of epiglottitis and meningitis.
We acknowledge help from Mrs C Roycroft for data on patients at Birmingham Maternity Hospital.

\section{References}

1 Gould JC, Duerden BI. Blood culture-current state and future prospects. J Clin Pathol 1983;36:963-77.

2 DeBlanc HJ, DeLand F, Wagner HN. Automated radiometric detection of bacteria in 2,967 blood cultures. Appl Microbiol 1971;22:846-9.

3 Brown DFJ, Warner M, Taylor CED, Warren RE. Automated detection of micro organisms in blood cultures by means of the Malthus microbiological growth analyser. J Clin Pathol 1984;37:65-9.

4 Murray PR. The future for blood cultures. In: Current concepts in blood cultures. London: Roche Products, 1985:5-13.

5 Dorn GL, Land GA, Wilson GE. Improved blood culture technique based on centrifugation: clinical evaluation. J Clin Microbiol 1979;9:391-6.

6 Sawhney D, Hinder S, Swaine D, Bridson EY. Novel method for detecting micro-organisms in blood cultures. J Clin Pathol 1986;39:1259-63.

7 King A, Bone G, Phillips I. Comparison of radiometric and gas capture system for blood cultures. J Clin Pathol 1986;39:661-5.

8 Santosham M, Moxon ER. Detection and quantitation of bacteraemia in childhood. $J$ Pediatr 1977;91:719-21.

9 Sullivan TD, LaScolea LJ, Neter E. Relationship between the magnitude of bacteraemia and the clinical disease. Pediatrics 1982;69:699-702.

10 LaScolea LJ, Dryja D, Neter E. Comparison of the quantitative direct plating method and BACTEC procedure for rapid diagnosis of Haemophilus influenzae bacteraemia in children. $J$ Clin Microbiol 1981;14:661-4.

11 Durbin WA, Szymczak EG, Goldmann DA. Quantitative blood cultures in childhood bacteraemia. $J$ Pediatr 1978;92:778-80.

12 Cowan ST, Steel JK. Manual for the identification of medical bacteria. Cambridge: Cambridge University Press, 1981.

13 Neal PR, Kleiman MB, Reynolds JK, Allen SD, Lemons JA, Peo-Lo Yu. Volume of blood submitted for culture from neonates. J Clin Microbiol 1986;24:353-6.

14 Carey RB. Clinical comparison of the Isolator 1.5 microbial tube and the Bactec Radiometric system for detection of bacteraemia in children. J Clin Microbiol 1984;19:634-8.

15 Welch DF, Scribner RK, Hensel D. Evaluation of a lysis direct plating method for pediatric blood culture. J Clin Microbiol 1985;21:955-8.

16 Meadow WL, Schwartz IK. Time course of radiometric detection of positive blood cultures in childhood. Pediatr Infect Dis 1986;5:333-6.

17 McLaughlin JC, Hamilton P, Scholes JV, Bartlett RC. Clinical laboratory comparison of lysis centrifugation and Bactec radiometric blood culture technique. J Clin Microbiol 1983;18:1027-31.

18 George RH. Paediatric septicaemia. In: Serious infections: treatment and prevention. London: Update publications, 1985: $138-50$.

19 Thomson RB, Vanzo SJ, Henry NK, Guenther KL, Washington JA. Contamination of cultures processed with the Isolator lysiscentrifugation blood culture tube. J Clin Microbiol 1984;19: 97-9.

Requests for reprints to: Dr R H George, Department of Microbiology, Birmingham Children's Hospital, Ladywood, Birmingham B16 8ET, England. 